\title{
Prevalence of intestinal parasitic infections among school aged children in Berber locality, River Nile State, Sudan 2017
}

\begin{abstract}
Background: Intestinal parasitic infections are amongst the most widespread infections throughout the globe. It is estimated that 3.5 billion people are affected, and that 450 million are ill as a consequence of these infections, the majority being children.
\end{abstract}

Justification: There is no previous study about the prevalence of intestinal parasitic infection among school aged children in Berber area.

Objectives: To know the Prevalence of the intestinal parasitic infections between schools aged children in Berber.

Method: Hundred primary school aged children were involved in the study, stool specimens were examined by direct wet preparation and formal ether centrifugation concentration method.

Result: Out of 100 students examined $87.2 \%$ had infection with intestinal parasites.

Conclusion: The prevalence of intestinal parasitic infection among the participants was very high.

Keywords: prevalence, intestinal parasite, infection

\section{Background}

Intestinal parasitic infections are amongst the most common infections throughout the world. It is estimated that 3.5 billion people are affected, and that 450 million are ill as a result of these infections, the majority being children. ${ }^{1}$ The earliest agents of human infection to have been observed were helminthic parasites, ${ }^{2}$ Parasitic diseases are responsible for considerable morbidity and mortality in humans and animals throughout the world. ${ }^{3}$

These infections are regarded as a serious public health problem, as they can cause iron deficiency anemia, growth retardation in children and other physical and mental health conditions. ${ }^{1,4-7}$ Intestinal parasites produce a variety of symptoms in those who are affected, most of which manifest themselves in gastrointestinal complications and general weakness, gastrointestinal complications include diarrhea, nausea, dysentery, and abdominal pain and abdominal discomfort. These symptoms negatively impact with nutritional status, including decreased absorption of micronutrients, loss of appetite, weight loss and intestinal blood loss that can often result in anemia(as D.latum [fish tape warm]) that absorb vitB12 and cause it is deficiency and lead to megaloblasic anemia). It may also cause physical and mental disabilities, delayed growth in children, and skin irritation around the anus and vulva. ${ }^{8}$

The high prevalence of these infections is closely correlated with poverty, poor environmental hygiene and impoverished health services. $^{9-11}$ The fecal oral route is significant in the transmission of parasitic infections to human via poor personal hygiene and environmental conditions such as contaminated soil and water sources with feces containing the infective stages of the parasite. (e.g., cysts of E. Histolytica, and ova of Ascar s Lumbricoides), Autoinfection: Few intestinal parasites may be transmitted to the same person by contaminated hand (external autoinfection) or by reverse peristalsis
Volume 7 Issue 2 - 2019

\section{Mosab Nouraldein Mohammed Hamad, Ayman Abdelrahman Mokhtar, Mazin alameldin, Yousif Mohammed Abkar, Muzameil Eltoum}

Department of Medical Parasitology, Faculty of Health Sciences, Elsheikh Abdallah Elbadri University, Sudan

\author{
Correspondence: Mosab Nouraldein Mohammed Hamad, \\ Department of Medical Parasitology, Faculty of Health Sciences, \\ Elsheikh Abdallah Elbadri University, Sudan, \\ Emailmusab.noor13@gmail.com
}

Received: February 25, 2019 | Published: March 27, 2019 (internal autoinfection). It is observed in (Crypto- sporidium Parvum, Taenia Solium, Enterobius Vermicularis, Strongyloides Stercoralis and Hymenolepis Nana), Contaminated soil and water: Soil polluted with human excreta containing eggs of the parasites can act as an important source of infection, e.g., hookworm, Ascaris species, Strongyloides species and Trichuris species. Water contaminated with human excreta containing cysts of E. Histolytica or Giardia Lamblia, can act as source of infection, Raw or under cooked meat: Raw beef containing the larvae (Cysticercus Bovis) and pork containing Cysticercus Cellulosae are some of the examples where undercooked meat acts as source of infection other sources of infection: Fish, crab or aquatic plants. ${ }^{12,13}$ Worm infection is believed to be imposing an unnecessary burden on many South African children and on the overall cost of health-care. ${ }^{14}$ Disadvantaged children are the most affected, especially those who live in densely populated and underserviced urban informal settlements as well as in some rural areas. ${ }^{14}$ World Health Assembly (WHA) member states, including South Africa, were urged to implement regular, non-selective de-worming of school-age children and young women by 2010 in areas where the prevalence of worm infestation is $50 \%$ or more. ${ }^{15}$

\section{Justification}

Currently, there is scarcity of available literature regarding the prevalence of parasitic infections from the locality; therefore, little is known about intestinal parasitic infections in the inhabitants of the Berber town, the study was carried out to fill that gap. Therefore, the aim of this study was to determine the prevalence of intestinal parasites in schools of Berber town.

\section{Objectives}

To know the Prevalence's of the intestinal parasites among primary schools children in Berber Town. 


\section{Materials}

Study design: This descriptive, cross- sectional study.

Study period: Carried out from January 2018 to March 2018.

Study area: Study was done in Berber town, which it is center of Berber locality in river Nile state, republic of Sudan, Berber locality divided in to four sectors, north sector, south sector, west sector, town sector. 152,377 live in it [26,230 of them live in the town] according to population census in 2008 .

Study population: This study performed in primary school children of Berber town.

Sample size: Twenty (100) school children, where chosen to participate in the study and sample size was 78 stool sample collected from children and these sample preserved in $10 \%$ formalin because that is necessary for preservation of fecal specimens is essential to maintain protozoan morphology and also to prevent further development of helminthes egg and larva.

Sampling: The techniques that will be used are the just wet mounting of the selected stool sample.

Data collection: Questionnaire will gather information according to certain questions.

Data analysis: The percentage of the prevalence of parasitic infection among participant was calculated.

Ethical consideration: The objective of the study was explained to the study participants and verbally informed consent was obtained.

\section{Selection criteria}

a. Inclusion criteria (class four students)

b. Exclusion criteria (other classes)

\section{Method}

The sample was stool, collected in clean \& dry plastic container, then added to it formalin for fixation, by wet preparation examine under microscope for detection of parasite.

\section{Result}

Out of 100 students examined $87.2 \%$ had infection with intestinal parasites.

\section{Conclusion}

The prevalence of intestinal parasite in Berber area primary schools was very high.

Recommendation: The prevalence of parasite was high so that something must do:

a) Health education specially in primary school;

b) Improve health care system;

c) Washing of hand before and eating and after defecation.

\section{Acknowledgments}

None.

\section{Conflicts of interest}

Authors declare that there is no conflict of interest.

\section{References}

1. Okyay P, Ertug S, Gultekin B, et al. Intestinal parasites prevalence and related factors in school children, a western city sample-Turkey. $B M C$ Public Health. 2004;4:64.

2. Gosling PJ. Dictionary of medical Parasitology. CRC Press; 2005. 408 p.

3. Jayaram Paniker CK. Text book of medical Parasitology. 6th ed. Jaypee Brothers Medical Publishers (P) Ltd; 2007.

4. Ostan I, Kilimcioğlu AA, Girginkardeşler N, et al. Health inequities: Lower socio-economic conditions and higher incidences of intestinal parasites. BMC Public Health. 2007;7:342.

5. Kwitshana ZL, Tsoka JM, Mabaso ML. Intestinal parasitic infections in adult patients in KwaZulu-Natal. S Afr Med J. 2008;98(9):709-711.

6. Alaofè $\mathrm{H}$, Zee J, Dossa R, et al. Intestinal parasitic infections in adolescent girls from two boarding schools in southern Benin. Trans $R$ Soc Trop Med Hyg. 2008;102(7):653-661.

7. Elliott AM, Kizza M, Quigley MA, et al. The impact of helminths on the response to immunization and on the incidence of infection and disease in childhood in Uganda: Design of a randomized, double blind, placebo-controlled, factorial trial of deworming interventions delivered in pregnancy and early childhood ISRCTN32849447. Clin Trials. 2007;4(1):42-57.

8. en.m.wikypedia.com

9. Ekpo UF, Odoemene SN, Mafiana CF, et al. Helminthiasis and hygiene conditions of schools in Ikenne, Ogun State, Nigeria. PLoS Negl Trop Dis. 2008;2(1):e146.

10. Uga S, Rai SK, Kimura K, et al. Parasites detected from diarrheal stool samples collected in Nepal. Southeast Asian J Trop Med Public Health. 2004;35(1):19-23.

11. Mehraj V, Hatcher J, Akhtar S, et al. Prevalence and factors associated with intestinal parasitic infection among children in an urban slum of Karachi. PLoS One. 2008;3(11):e3680.

12. Sastry AS, Bahat S. Essential of medical Parasitology. 2nd ed. Jp Medical Ltd; 2014. 288 p.

13. Nyarango RM, Aloo PA, Kabiru EW, et al. The risk of pathogenic intestinal parasite infections in Kisii Municipality, Kenya. BMC Public Health. 2008;8:237.

14. Fincham J, Dhansay A. Worms in SA's Children-MRC Policy Brief; 2006.

15. Adams VJ, Markus MB, Adams JF, et al. Paradoxical helminthiasis and giardiasis in Cape Town, South Africa: Epidemiology and control. Afr Health Sci. 2005;5(2):131-136. 